\title{
Correction to: Crop Establishment in Direct-Seeded Rice: Traits, Physiology, and Genetics
}

Fergie Ann Quilloy, Benedick Labaco, Carlos Casal Jr, and Shalabh Dixit

\section{Correction to:}

\section{Chapter 6 in: J. Ali, S. H. Wani (eds.), Rice Improvement, https://doi.org/10.1007/978-3-030-66530-2_6}

\begin{abstract}
"Owing to an error on the part of the editor and corresponding chapter author, the author sequence in the chapter opening page of chapter Crop Establishment in Direct-Seeded Rice: Traits, Physiology, and Genetics was presented wrongly. The author sequence has now been updated to be Fergie Ann Quilloy, Benedick Labaco, Carlos Casal Jr., Shalabh Dixit in the chapter opening page, table of contents, and wherever applicable throughout the book."
\end{abstract}

